\title{
Flooding Affects Snap Bean Yield and Genotypic Variation in Leaf Gas Exchange and Root Growth Response
}

\begin{abstract}
Benyamin Lakitan ${ }^{1}$, David W. Wolfe ${ }^{2}$, and Richard W. Zobel ${ }^{3}$
Cornell University, Ithaca, NY 14853

Additional index words. Phaseoh vulgaris, hypoxia, waterlogging, photosynthesis, stomatal conductance, leaf water potential, adventitious roots

Abstract. Greenhouse experiments were conducted in 1987 and 1988 to evaluate the effect of timing of a 4-day flooding stress on growth and yield of snap bean (Phaseolus vulgaris L. cv. Bush Blue Lake 274, BBL). Plant survival was reduced when flooding was imposed at postflowering growth stages, but most plants survived when flooded before flowering or when reproductive development was prevented by deflowering. Early yields of surviving plants were very low in all flooded treatments, regardless of timing, in both years. Total yield response to timing of flooding was linear in 1987, with lowest yields when flooding was imposed at later growth stages. The trend was not linear in 1988, but in both years the latest flooding treatment (36 days after planting) had few surviving plants and no measurable pod yield. Additional greenhouse experiments revealed that leaf conductance of BBL and another bean cultivar, Luna (LN), declined within the first day of flooding. This decline was concomitant with one in leaf water potential and photosynthesis (Pn) in BBL, but decline of these responses occurred 1 to 2 days later for LN. After 4 days of flooding, Pn fell to near 0 for BBL, and to $15 \%$ of the prestress value for $L N$. Pn of both cultivars had recovered to 18.5 $\mu \mathrm{mol} \cdot \mathrm{m}^{-2} \cdot \mathrm{s}^{-1} 10$ days after termination of flooding. LN had a larger adventitious root biomass, higher percentage of adventitious roots, and a consistently lower leaf: root ratio than BBL during recovery.
\end{abstract}

Legumes are a primary food source in many regions of the world and are important as rotational crops that improve soil nitrogen status and help sustain agricultural productivity. Production of beans and other legumes is frequently constrained in northern latitudes by heavy spring rainfalls that cause temporary flooding on soils with poor drainage. Many developing nations must consider the use of marginal lands with a high risk of flooding to increase food production for expanding populations. Selection of crops, cultivars, and planting dates under these circumstances requires more information regarding flood duration and timing effects on crop growth and yield. More basic information on genotypic variation in physiological and morphological responses to flooding stress is needed to improve breeding for tolerant cultivars.

Some legume species have been reported to be able to withstand flooding for up to 20 days (Heinrich, 1970), but growth of bean ( $P$. vulgaris) can be significantly suppressed within the first day of flooding (Wadman-van Schravendijk and van Andel, 1985), and growth suppression increases with longer duration of stress (Kahn et al., 1985; Singh et al., 1991). Root growth is frequently more severely suppressed than shoot growth (Kahn et al., 1985; Wadman-van Schravendijk and van Andel, 1985).

The significance of adventitious roots as a mechanism for maintaining active root surface area during flooding and recovery has been emphasized in the literature for many years (review: Jackson and Drew, 1984). However, Wample and Reid (1978) found no apparent contribution of adventitious roots to

Received for publication 12 Nov 1991. Accepted for publication 13 May 1992. This work was supported by USDA Hatch Project grant NYC 161422 (D.W.W.) and a USAID research grant (B.L.). WC thank M.H. Dickson for consultation regarding cultivar selection and experimental design. The cost of publishing this paper was defrayed in part by the payment of page charges. Under postal regulations, this paper therefore must be hereby marked advertisement solely to indicate this fact.

Current address: Fakultas Pertanian, Universitas Sriwijaya, Palembang 30139, Indonesia.

Corresponding author. Dept. of Fruit and Vegetable Sciences.

${ }^{3}$ Dept. of Soil, Crop, and Atmospheric Sciences. survival of flooded sunflower (Helianthus annuus L.) plants, and Poysa et al. (1987) reported that adventitious root development did not differ between flood tolerant and susceptible tomato (Lycopersicon esculentum Mill.) cultivars. Kahn et al. (1985) compared three black bean ( $P$. vulgaris) cultivars and found significant differences in adventitious root biomass, but shoot : root ratios and increases in adventitious roots on a relative basis during flooding were similar among the cultivars evaluated. More research is needed to determine the contribution of adventitious roots to flooding tolerance within Phaseolus, and the extent of genotypic variation in adventitious root growth during flooding and recovery.

A decline in leaf conductance (gL) and C assimilation usually occurs within the first 1 to 3 days of imposition of flooding stress in P. vulgaris (Moldau, 1973; Singh et al., 1991). High leaf-to-air vapor pressure deficits affect plant-water relations and can hasten flooding-induced stomata1 closure (Lakitan and Wolfe, 1990). Genotypic variation in leaf gas exchange response to flooding has been reported for soybean (Glycine max L.) (Oosterhuis et al., 1990), but this has not been evaluated in P. vulgaris.

Yield reductions of flooded $P$. vulgaris have been documented (Tabbada and Flores, 1982), but yield response has not been studied as intensively as for some other legume species. Larger yield reductions when flooding is imposed at reproductive rather than vegetative growth stages has been reported for soybeans (Griffin and Saxton, 1988; Oosterhuis et al., 1990; Scott et al., 1989), mungbean [Vigna radiata (L.) Wilczek] (Trung et al., 1985) and tomato (Lopez and del Rosario, 1983). It remains unclear whether sensitivity to flooding is directly associated with hormonal changes occurring during reproductive development or is due to other factors, such as a larger leaf area increasing transpirational losses at later growth stages. We found no reports investigating sensitive growth stages for snap bean.

Abbreviations: BBL, 'Bush Blue Lake 274'; DAP, days after planting; g,, leaf conductance; LN, 'Luna'; Pn, photosynthesis; $\Psi_{\mathrm{L}}$, leaf water potential. 
The primary objectives of this study were to: 1) compare the effect of flooding at pre- and postflowering growth stages on plant survival and yield of snap bean; and 2) evaluate genotypic variation within $P$. vulgaris in respect to leaf gas exchange response to flooding and root growth during recovery.

\section{Materials and Methods}

Timing of flooding (Expt. 1). Greenhouse experiments were conducted in Fall 1987 and 1988 to compare the effects of a 4day flooding treatment imposed at 20, 24, 28, 32, or 36 days after planting (DAP). Preliminary experiments (Lakitan, 1989) indicated that 4 days of flooding imposed an appropriate level of stress intensity for our objectives. Timing treatments were selected to bracket anthesis; flowering began between 28 and 30 DAP in both years.

Four seeds of $P$. vulgaris, 'Bush Blue Lake 274' (BBL), were planted into each $20-\mathrm{cm}$-diameter white plastic pot containing 3 liters of a 50 sterilized peat : 50 vermiculite mix (v/v). Limestone, superphosphate, and calcium nitrate were added to the mix at rates of $4.45,1.79$, and $1.32 \mathrm{~kg} \cdot \mathrm{m}^{-3}$, respectively. Micronutrients added were (grams) $8.3 \mathrm{Mn}, 23.4 \mathrm{Fe}, 2.5 \mathrm{Cu}, 8.3$ $\mathrm{Zn}, 1.3 \mathrm{~B}$, and $0.1 \mathrm{Mo} / \mathrm{m}^{3}$ of mix. Twelve and six replications of each timing treatment and an unflooded control were planted in 1987 and 1988, respectively. Pots were arranged in a completely randomized design and rerandomized every 2 to 3 days to minimize location effect. Previous experiments conducted in the same greenhouse setting indicated that block designs were not efficient because environmental gradients were unpredictable and nonlinear. Plants were thinned to one per pot at $\approx 7$ DAP. Plants were fertilized weekly with $\left(\mathrm{mg} \cdot \mathrm{liter}^{-1}\right) 450 \mathrm{~N}$ (53\% in nitrate form), $210 \mathrm{P}$, and $420 \mathrm{~K}$. Greenhouse settings maintained temperatures between 21 and $28 \mathrm{C}$ (day)/15 to $20 \mathrm{C}$ (night), and daytime relative humidity between $60 \%$ and $70 \%$. Supplemental overhead lighting maintained a minimum 12-h photoperiod throughout the experiment.

Flooding was accomplished by placing each pot into a larger pot sealed with plastic, and maintaining the water level $1 \mathrm{~cm}$ above the soil surface for 4 days. A 1-cm layer of sand covered the mix to prevent the mix from floating during flooding. Flooding was terminated by removal of the inner pot from the sealed pot, allowing rapid free drainage.

The number of plants that did not survive flooding treatment was recorded at the end of the flooded period. Yield and biomass data were collected on surviving plants. Fully developed pods (at marketable stage for fresh market) were harvested four times during the growing period, with the first two harvest dates defined as early yield. Number and fresh and dry weights of the pods were recorded at each harvest. After the final harvest, the entire above-ground portion of the plants was harvested, dried at $70 \mathrm{C}$ for 3 to 5 days, and weighed. Harvest index was defined as the ratio of cumulative pod dry weight divided by total aerial biomass dry weight. Statistical significance of the control vs. flooded contrast, and orthogonal polynomial analysis for equally spaced treatments were calculated according to Steel and Torrie (1980).

As part of the 1988 experiment, 12 additional plants were grown to determine leaf : root dry weight ratios at the onset of flooding and to evaluate the effect of prevention of reproductive development on survival after flooding at 20, 28, and 32 DAP. Six plants from each treatment were destructively harvested when flooding was initiated, roots were separated from the soil by flushing with water, and leaf, root, and stem dry weights determined. The remaining six plants of each treatment were ex- amined each day throughout the experiment, and any developing flower buds were removed. Flooding was imposed and plant survival counts and final biomass harvest were conducted as described for nondeflowered (normal) plants. A $x^{2}$ test (Steel and Torrie, 1980) based on plant counts was used for pair-wise comparisons of survival of deflowered and normal plants.

Root growth during recovery (Expt. 2). Separate experiments were conducted in Spring and Summer 1988 to evaluate genotypic variation in root growth during recovery from a 4-day flooding stress. BBL and 'Luna' (LN), a reportedly flood-tolerant $P$. vulgaris cultivar, were compared in each experiment. The flood tolerance of LN was based primarily on greenhouse and field observations of relatively more rapid shoot and root growth recovery after short-term flooding stress (M.H. Dickson, personal communication). Seed for LN were obtained from the National Seed Storage Laboratory, Colorado State Univ., Fort Collins.

A 4-day flooding treatment was imposed at 20 DAP, while plants were still at a vegetative (preflowering) stage of growth. Cultural practices, greenhouse settings, and flooding technique were as described for Expt. 1. Plants were destructively harvested for measurement of toot and leaf biomass at $0,1,2,3$, 5 , and 7 days after termination of flooding. The root system was separated into three major components: adventitious, basal, and tap (Stoffella et al., 1979). Four plants were measured from each cultivar at each harvest, and the entire experiment was conducted twice, for a total of eight replications per measurement. Pots were arranged in a completely randomized design.

Before each destructive harvest, the terminal leaflet of' the second trifoliate leaf of each plant was measured for leaf water potential $\left(\Psi_{\mathrm{L}}\right)$ between 1200 and $1400 \mathrm{HR}$ using a pressure bomb (Soil Moisture Equipment Corp., Santa Barbara, Calif.). The second trifoliate was near full expansion during the recovery period.

Leaf gas exchange Expt. 3). The same cultivars were compared for their leaf gas exchange responses to 4 days of flooding imposed at 20 DAP. Plants were grown in the greenhouse in May and June 1987 for this purpose. Cultural practices, greenhouse settings, and flooding technique were as described for Expts. 1 and 2. Measurements were made on the terminal leaflet of second or third trifoliate leaves near full expansion (30 to 40 $\mathrm{cm}^{2}$ leaf area). The entire leaflet was enclosed within a $10 \mathrm{x}$ $10 \mathrm{~cm}$ leaf cuvette of a steady-state, semi-closed, null-balance gas exchange system (PACsys 9900, Data Design Group, La Jolla, Calif.), using a LI-6250 infrared gas analyzer (LI-COR, Lincoln, Neb.). The system allows the user to select $\mathrm{CO}_{2}$ concentration, leaf temperature, and $\mathrm{RH}$ to be maintained within the cuvette. All measurements in this experiment were made between 1100 and $1500 \mathrm{HR}$, at $335 \mu \mathrm{CO}_{2} /$ liter, 28C, 55\% RH, and photosynthetic photon flux density of $650 \mu \mathrm{mol} \cdot \mathrm{m}^{-2} \cdot \mathrm{s}^{-1}$. Gas exchange values were calculated as described by Ball (1987).

Leaf gas exchange was measured on a minimum of six plants of each cultivar before flooding, at 1,2, 3, and 4 days during the flooded interval, and at 2 and 10 days after termination of flooding. Additional plants were grown for pressure bomb measurement of $\Psi_{\mathrm{L}}$ at 1 and 3 days after flooding for both cultivars, with a minimum of four replications per measurement.

\section{Results and Discussion}

Timing of flooding. Flooding BBL for 4 days delayed maturity, and early yields were severely suppressed in both years, regardless of timing of the stress treatment (Table 1). Total yields were also significantly reduced by flooding in both years, 
Table 1. Survival, pod yield, yield components, total above-ground biomass, and harvest index (HI) of snap bean plants exposed to 4 days of flooding at various DAP; the control was not flooded. Data are based on surviving plants only.

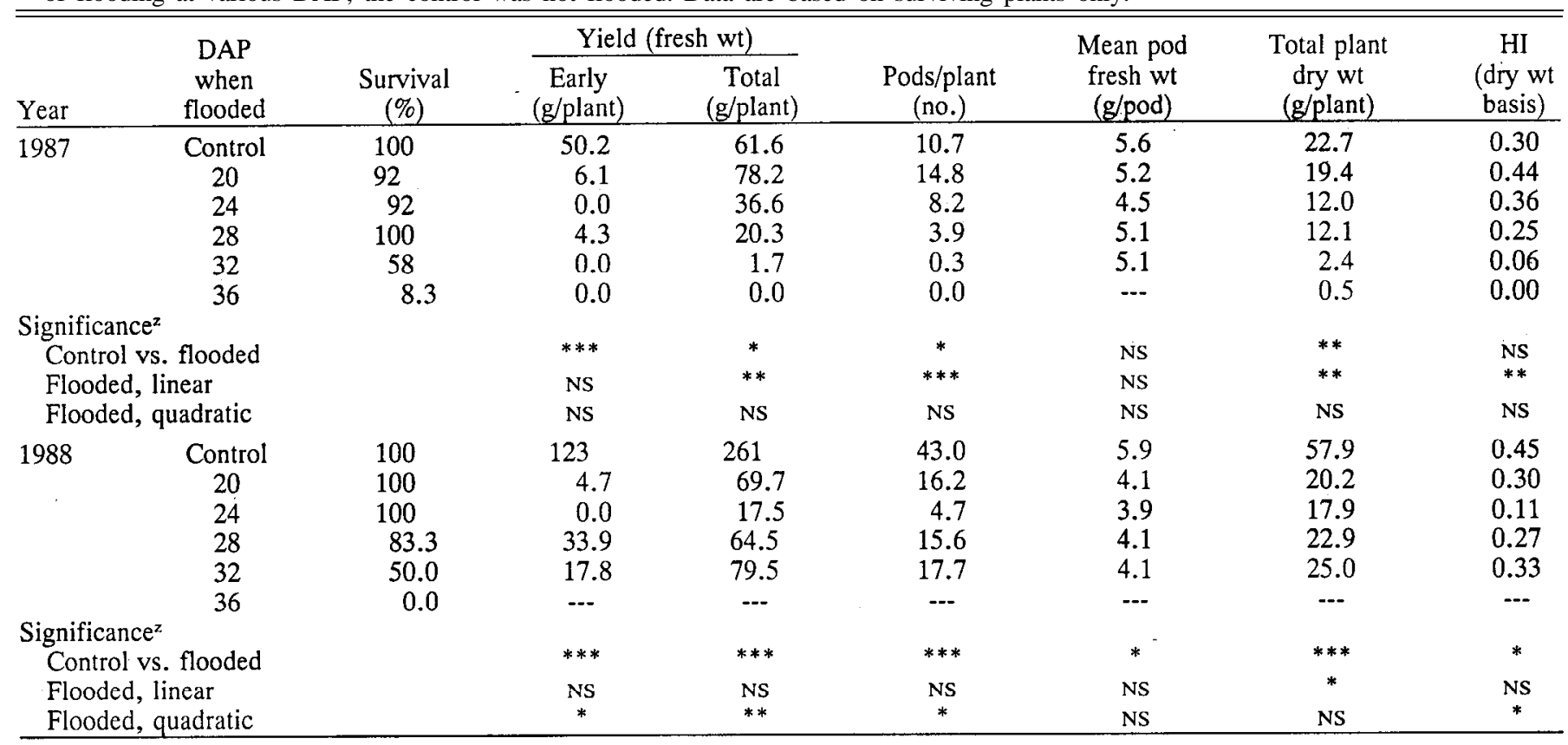

${ }^{2}$ Data for 36 DAP are not included in statistical analyses because of insufficient number of surviving plants.

Ns,*,**,***Nonsignificant or significant at $P=0.05,0.01$, or 0.001 , respectively.

and in 1987, the response to timing of flooding was linear, with the lowest total yields occurring when stress was imposed at later growth stages, after flowering had begun (>28 DAP). Flooding before flowering had minimal impact on total yield in 1987 (independent orthogonal contrasts between the control and 20 and 24 DAP treatments not significant at $P=0.05$ ), but in 1988 total yields of flooded plants were never $>30 \%$ of the control, regardless of timing. Total yield response to timing of flooding was quadratic in 1988 because yields were lower in the 24 DAP treatment than for 28 and 32 DAP. However, in both years the number of surviving plants declined when stress was imposed after flowering, and no measurable pod yield was obtained in either year when flooding was imposed as late as 36 DAP.

The high plant mortality when flooding was imposed after flowering is not reflected in the yield data of surviving plants (Table 1) but is-of importance when considering potential yield impact on a per unit land area basis. We initially suspected that a larger leaf area at later growth stages may contribute to the reduction in plant survival by increasing transpirational surface area during flooding stress. However, leaf : root dry weight ratios, which reflect the balance between water demand and supply, were measured in 1988 and found not to be significantly different $(\mathrm{P}<0.05)$ at 20, 28, and 32 DAP (leaf : root ratios of 4.6, 5.6, and 4.9, respectively).

Survival of plants flooded at later growth stages (28 and 32 DAP) was reduced $17 \%$ to $50 \%$, but plants of the same chronological age were not adversely affected (survival $=100 \%$ ) when reproductive development was prevented by removal of all developing flower buds (Table 2). Increased sensitivity to flooding stress during reproductive stages was reported for soybean where flooding for up to 8 days at a vegetative growth stage (V6) had minimal impact on yield, while flooding at a later reproductive stage (R2) reduced yields per unit land area by $10 \%$ to $50 \%$ (Griffin and Saxton, 1988). A greater sensitivity
Table 2. Effect of prevention of reproductive development (flower bud removal) on plant survival and final biomass (dry weight) production of surviving snap bean plants exposed to 4 days of flooding at various DAP in 1988. Flowering began at 28 DAP.

\begin{tabular}{|c|c|c|c|c|c|}
\hline \multirow[b]{3}{*}{ Measurement } & \multirow{3}{*}{$\begin{array}{c}\text { Plants } \\
\text { deflowered }\end{array}$} & \multicolumn{4}{|c|}{ Flooding treatment } \\
\hline & & \multirow[b]{2}{*}{ Control } & \multicolumn{3}{|c|}{ DAP when flooded } \\
\hline & & & 20 & 28 & 32 \\
\hline \multirow[t]{3}{*}{ Plant survival $(\%)$} & Yes & 100 & 100 & 100 & 100 \\
\hline & No & 100 & 100 & 83 & 50 \\
\hline & & NS & NS & 0 & $* * *$ \\
\hline \multirow{3}{*}{$\begin{array}{l}\text { Vegetative biomass } \\
\text { (g/plant) }\end{array}$} & Yes & $57.7^{2}$ & 20.6 & 9.0 & 12.2 \\
\hline & No & $31.8^{z}$ & 13.6 & 16.9 & 16.9 \\
\hline & & $* *$ & NS & & NS \\
\hline \multirow{2}{*}{$\begin{array}{l}\text { Total biomass } \\
\text { (g/plant) }\end{array}$} & Yes & $57.7^{2}$ & 20.6 & 9.0 & 12.2 \\
\hline & & NS & NS & $* *$ & $* *$ \\
\hline
\end{tabular}

LControl vs. flooded statistical contrast within row significant at $P=$ 0.001 .

Ns $*, * *, * * *$ Nonsignificant or significant at $P=0.05,0.01$, or 0.001 , respectively, by $t$ test (biomass) or $x^{2}$ test (plant survival).

to flooding at reproductive stages has been corroborated in other studies with soybean (Oosterhuis et al., 1990; Scott et al., 1989) and also reported in other species such as mungbean (Trung et al., 1985) and tomato (Lopez and del Rosario, 1983). The reasons for this sensitivity are not clearly understood. The similar leaf : root ratios among plant ages used in our experiments suggest that poorer plant water balance was not a cause of higher mortality at later growth stages. However, root dry weight may not accurately indicate active root surface area. Stanley et al. (1980) suggested that individual soybean roots were more tolerant of excessive soil water at vegetative than reproductive stages. Also, stomata1 responses to flooding will affect transpirational water losses per unit leaf area. Additional study will be required to further test the hypothesis that increased plant 
mortality at later growth stages is due to reproductive development per se and to determine possible controlling hormonal mechanisms and the role of plant-water relations.

Reproductive development of BBL began well before plants reached maximum size, and flooding at the growth stages used in our study affected yield (of surviving plants) primarily by causing smaller plants and fewer pods per plant rather than a reduction in weight per pod or average seed weight (Table 1). This result is similar to those reported for broad beans (Vicia faba L. minor) grown under high water table conditions where plant height was correlated with yield in cultivar comparisons but average seed weight was not affected by flooding (Alvino et al., 1983). In contrast, Griffin and Saxton (1988) found that the reduced height of soybeans flooded at the V6 vegetative stage was compensated for by increased branching and seeds per pod so that yields were not affected. These results indicate that genotypic differences in compensatory ability and in the relationship between vegetative and reproductive development at the time of flooding stress have a profound effect on the nature of the yield response.

Root growth during recovery. Root growth of both cultivars began to resume $\approx 3$ days after termination of flooding (Fig. 1). BBL had significantly less basal, tap, and adventitious root biomass than LN throughout the experiment, and total root dry weight of BBL was about half that of $\mathrm{LN}$ at the end of the recovery period. The highest relative rate of growth was observed in adventitious roots, with a similar 6-fold increase for both cultivars during the 7-day recovery period. LN maintained a larger adventitious root biomass than BBL on an absolute basis because of a larger root system in general and a higher proportion of root biomass of this morphological type (5\% to $11 \%$ of LN roots were adventitious compared with $2 \%$ to $5 \%$ adventitious roots for BBL).

LN began the recovery phase with a lower leaf : root ratio than BBL, and this ratio declined by an additional $35 \%$ for LN and $25 \%$ for BBL during the 7 -day recovery period (Fig. 2A). This decline reflects more rapid root than shoot growth for both cultivars during recovery, as reported by Kahn et al. (1985), working with black beans. They also reported that the reverse was true during the flooded period and root growth was more suppressed than shoot growth. We made similar observations in preliminary flood duration experiments with BBL (Lakitan, 1989). A shift in partitioning pattern during recovery so that root growth is favored may improve water and nutrient supply and be of adaptive advantage when hypoxic conditions have impaired the function of existing roots.

$\Psi_{\mathrm{L}} \mathrm{S}$ measured immediately after termination of flooding (day 0) were 0.3 MPa more negative for BBL than for LN (Fig. 2B). The more favorable water balance maintained by LN may be associated with the higher ratio of adventitious roots per unit transpirational surface area and be an advantage during recovery from flooding, particularly when evaporative demand is high and hydraulic conductivity of existing roots has been adversely affected by stress. Wadman-van Schravendijk and van Andel (1985), also working with beans, reported that recovery of leaf turgor, abscisic acid (ABA) levels, and $g_{\mathrm{L}}$ coincided with the onset of adventitious root formation. More information will be required to determine whether the distinctions between $\mathrm{BBL}$ and LN that we have identified indicate heritable stress response mechanisms, or simply reflect cultivar differences in partitioning and growth potential.

Leaf gas exchange. Photosynthetic rate of BBL declined to $\approx 40 \%$ of the prestress level within the first $24 \mathrm{~h}$ of flooding
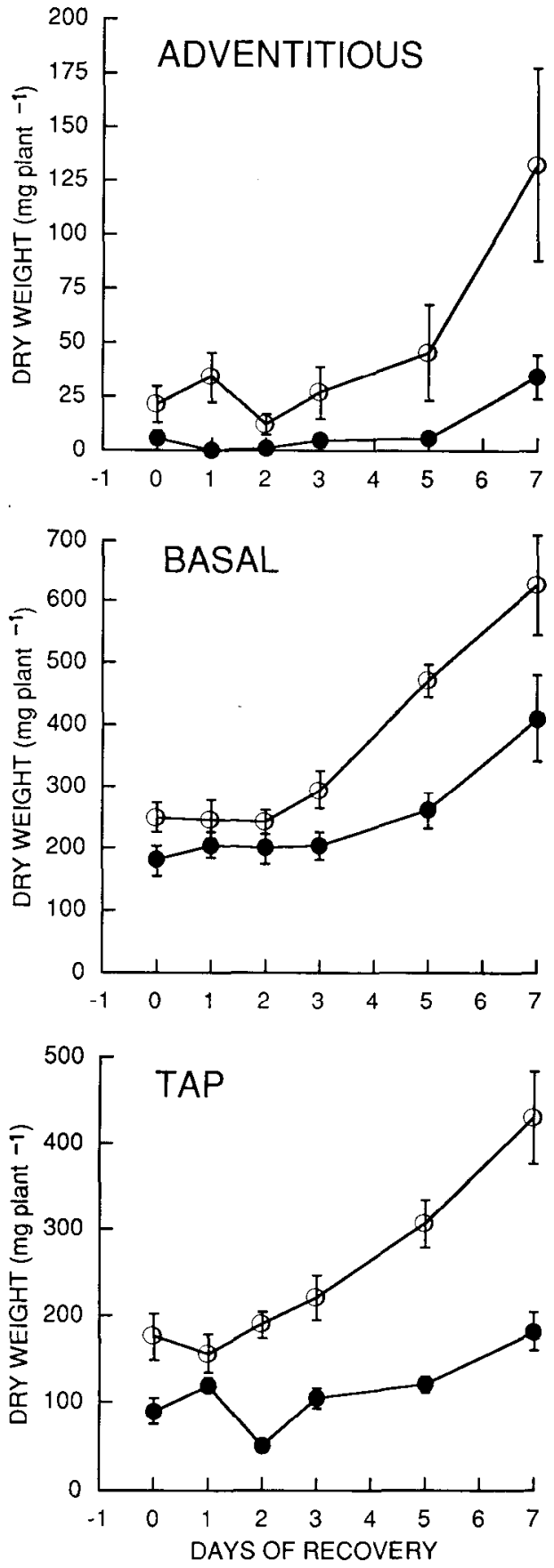

Fig. 1. Dry weight of adventitious, basal, and tap roots during a 7day recovery period following 4 days of flooding of Phaseolus vulgaris cultivars BBN (solid symbols) and LN (open symbols). Each value is the mean of eight replications $\pm \mathrm{SE}$.

(Fig 3A). In contrast, Pn of LN did not significantly decline until $48 \mathrm{~h}$ of flooding. After 4 days of flooding, Pn had declined to $2 \%$ and $15 \%$ of the prestress level for BBL and $\mathrm{LN}$, respectively. The delayed Pn decline, plus an earlier onset of recovery of Pn, may provide some adaptive advantage for $\mathrm{LN}$ under short-term flooding stress. However, assimilation rates were $<3$ $\mu \mathrm{mol} \cdot \mathrm{m}^{-2} \cdot \mathrm{s}^{-1}$ for both cultivars after 4 days of flooding, and both recovered to similar assimilation rates 10 days after termination of stress. The final $\mathrm{Pn}$ rate for $\mathrm{LN}$ of $18.5 \mu \mathrm{mol} \cdot \mathrm{m}^{-2} \cdot \mathrm{s}^{-1}$ represented a slight (13\%) reduction compared with Pn measured before flooding. Although this reduction was statistically significant (t test, $P<0.05$ ), it is difficult to be certain from 

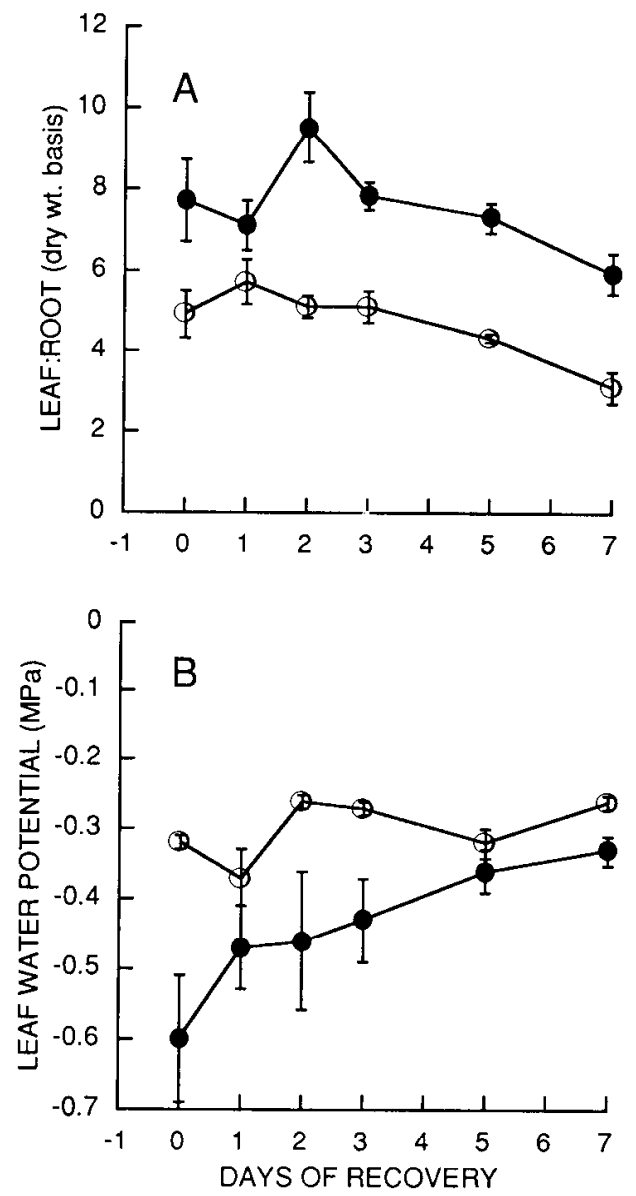

Fig. 2. Leaf : root ratio (A) and midday leaf water potential (B) measured during a 7-day recovery period following 4 days of flooding of Phaseolus vulgaris cultivars BBN (solid symbols) and LN (open symbols). Each value is the mean of eight replications \pm SE.

our data whether this indicates a lack of ability to completely recover, or simply reflects normal variability and/or leaf or plant age effects on photosynthetic capacity. Photosynthetic recovery was complete for BBL, which is in contrast with results reported by Singh et al. (1991), where Pn for the same cultivar did not fully recover even when flooded for only 1 day. They terminated measurements at 7 days of recovery, however.

A significant decline in $\mathrm{g}_{\mathrm{L}}$ was observed within the first day of flooding for both BBL and LN (Fig. 3B). This change was concomitant with a decline in $\Psi_{\mathrm{L}}$ from $-0.33 \mathrm{MPa}$ (prestress) to $-0.94 \mathrm{MPa}$ for BBL. In contrast, $\Psi_{\mathrm{L}}$ of $\mathrm{LN}$ was unaffected $(-0.38 \mathrm{MPa})$ after 1 day of flooding (difference between cultivars significant at $P<0.05$ ). Leaf water potential of both cultivars had declined by the 3rd day, however. Leaf conductance did not return to prestress values after 10 days of recovery in either cultivar (Fig. 3B). The relationship between Pn and gL changed after flooding stress, tending to increase individual leaf water use efficiency as discussed with regard to previous experiments (Lakitan and Wolfe, 1990).

The observation that $g_{L}$ of $L N$ declined before changes in $q_{L}$ provides additional evidence that stomata of flooded bean plants initially may be regulated by factors other than leaf turgor. Wadman-van Schravendijk and van Andel (1985) reported that declines in $\mathrm{g}_{\mathrm{L}}$, transpiration, and growth preceded significant changes in leaf water status in flooded $P$. vulgaris, and initial increases in leaf $\mathrm{ABA}$ levels were more closely correlated with $\mathrm{g}_{\mathrm{L}}$ than with $\Psi_{L}$. Hiron and Wright (1973) also reported a rapid rise in
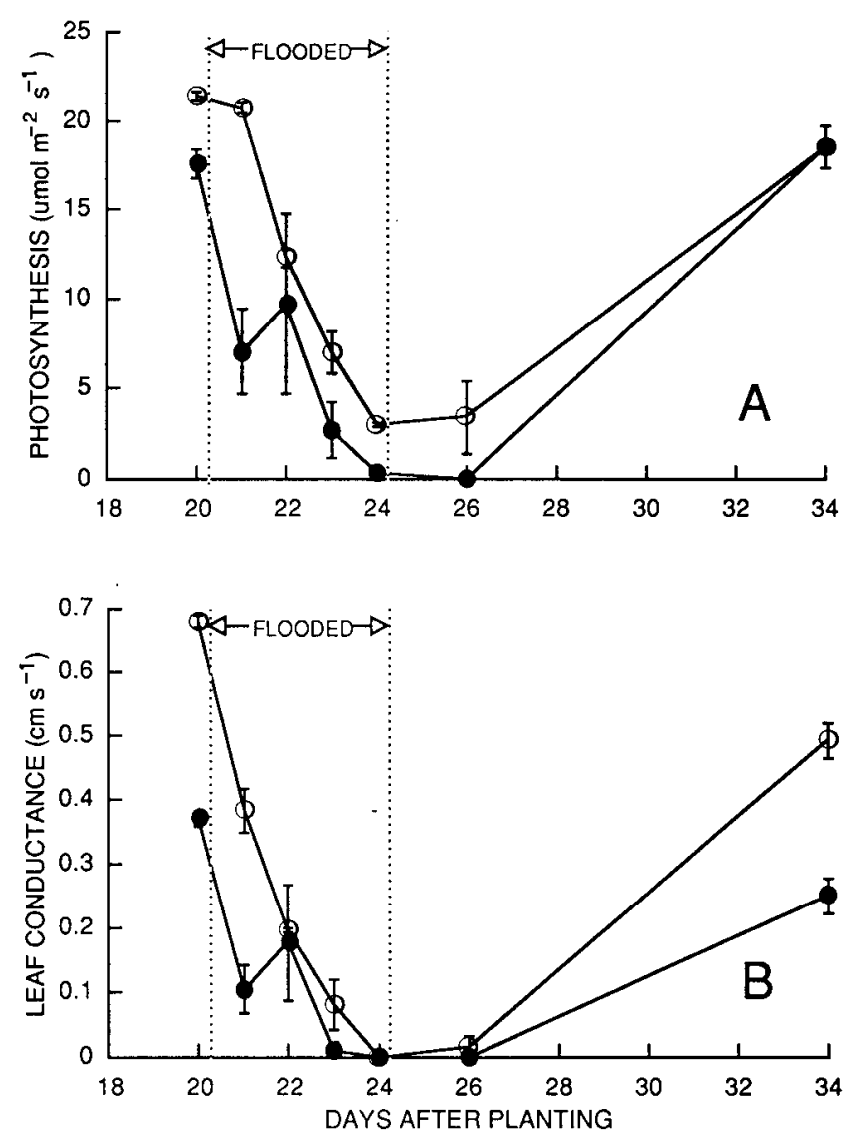

Fig. 3. Midday net photosynthesis (A) and leaf conductance (B) measured just before, during, and after a 4-day flooding stress imposed at 20 days after planting to Phaseolus vulgaris cultivars BBL (solid symbols) and LN (open symbols). Each value is the mean of six replications \pm SE. Midday leaf water potentials on day 21 were -0.94 $\mathrm{MPa}(\mathrm{BBL})$ and $-0.38 \mathrm{MPa}(\mathrm{LN})$, and on day 23 were $-1.99 \mathrm{MPa}$ (BBL) and $-1.87 \mathrm{MPa}(\mathrm{LN})$. See text for discussion.

ABA in flooded $P$. vulgaris. Bradford (1983) concluded that a combination of ABA accumulation in the leaves and decreased cytokinin supply from the roots was associated with stomatal closure in flooded tomato plants. The decrease in cytokinins also resulted in lowered ribulose 1,5 bisphosphate carboxylase/ oxygenase regeneration capacity in flooded tomato and a reduction in photosynthesis without a reduction in bulk leaf water status.

Wadman-van Schravendijk and van Andel (1985) found that when $\Psi_{\mathrm{L}}$ finally declined in bean plants after the 3rd day of flooding, it was accompanied by a rapid rise in leaf $\mathrm{ABA}$ and a further decline in $\mathrm{g}$,. This relationship suggests that although a change in $\Psi_{\mathrm{L}}$ is not a prerequisite for stomatal response to flooding, the early decline in $\Psi_{\mathrm{L}}$ that we observed in BBL may have exacerbated flooding stress effects on leaf gas exchange for that cultivar. One possible explanation for the earlier decline in $\Psi_{L}$ for BBL compared with $\mathrm{LN}$ would be differences in sensitivity of root hydraulic conductivity to flooding, but this was not measured in our study. Cultivar differences in leaf : root ratio (Fig. 2A) may have played an important role by altering the balance between water supply and evaporative demand.

To summarize, maturity was delayed and early yields were significantly reduced by 4 days of flooding in both years of our greenhouse study, regardless of timing of stress imposition. Yield 
losses of surviving plants were primarily associated with smaller plant size and fewer pods per plant. Total yields were also suppressed by flooding, particularly when stress was imposed at later growth stages. Plant survival, and therefore total yield potential, was more sensitive to flooding imposed after reproductive development had begun (28 DAP). In both years, few plants survived and there was no measurable pod yield when flooding was imposed at 36 DAP.

Genotypic comparisons indicated that $\mathrm{g}_{\mathrm{L}}$ began to decline within the first day of flooding for both BBL and LN. The initial stomata1 response coincided with a decline in $\Psi_{\mathrm{L}}$ for BBL, but $\Psi_{\mathrm{L}}$ decline occurred later for $\mathrm{LN}$. The delayed decline in $\Psi_{\mathrm{L}}$ for LN may be due to the lower leaf : root ratio for that cultivar and beneficial effects this had on the balance between water supply and demand. Other factors observed in our study that may be of adaptive advantage for LN during short-term flooding and recovery were a higher proportion of root biomass comprised of adventitious roots and a slower decline and more rapid recovery of Pn. However, Pn of BBL eventually recovered (after 10 days) to $>100 \%$ of prestress values, whereas LN recovery was not complete ( $87 \%$ of prestress Pn rate). Additional research will be required to determine how these differences influence growth and yield response to flooding in the field.

\section{Literature Cited}

Alvino, A., G. Zerbi, L. Frusciante, and L.M. Monti. 1983. Evaluation of field bean lines grown with a shallow water table maintained at different levels. Field Crops Res. 6:179-188.

Ball, J.T. 1987. Calculations related to gas exchange, p. 445-476. In: E. Zeiger, G.D. Farquhar, and I.R. Cowan (eds.). Stomata1 function. Stanford Univ. Press, Stanford, Calif.

Bradford, K.J. 1983. Effects of soil flooding on leaf gas exchange of tomato plants. Plant Physiol. 73:475-479.

Griffin, J.L. and A.M. Saxton. 1988. Response of solid-seeded soybean to flood irrigation. II. Flood duration. Agron. J. 80:885-888.

Heinrich, D.H. 1970. Flooding tolerance of legumes. Can. J. Plant Sci. 50:435-438.

Jackson, M.B. and M.C. Drew. 1984. Effects of flooding on growth and metabolism of herbaceous plants, p. 47-128. In: T.T. Kozlowski (ed.). Flooding and plant growth. Academic, Orlando, Fla. Kahn, B.A., P.J. Stoffella, R.F. Sandsted, and R.W. Zobel. 1985.
Influence of flooding on root morphological components of young black beans. J. Amer. Soc. Hort. Sci. 110:623-627.

Lakitan, B. 1989. Morphological and some physiological responses of bean (Phaseolus vulgaris L.) to flooding. PhD Diss., Cornell Univ., Ithaca, N.Y.

Lakitan, B. and D.W. Wolfe. 1990. Effects of vapor pressure gradient on leaf gas exchange in flooded snap bean (Phaseolus vulgaris L.). Indon. J. Trop. Agr. 2(1):6-13.

Lopez, M.V. and D.A. del'Rosario. 1983. Performance of tomatoes (Lycopersicon Zycopersicum (L.) Karsten) under waterlogged condition. Phillipine J. Crop Sci. 8:75-80.

Moldau, H. 1973. Effects of various water regimes on stomata1 and mesophyll conductance of bean leaves. Photosynthetica 7:1-7.

Oosterhuis, D.M., H.D. Scott, S.D. Wullschleger, and R.E. Hampton. 1990. Photosynthetic and yield responses of two soybean cultivars to flooding. Arkansas Farm Res. 39:11.

Poysa, V.W., C.S. Tan, and J.A. Stone. 1987. Flooding stress and the root development of several tomato genotypes. HortScience 22:2426.

Scott, H.D., J. DeAngulo, M.B. Daniels, and L.S. Wood. 1989. Flood duration effects on soybean growth and yield. Agron. J. 81:631636.

Singh, B.P., K.A. Tucker, J.D. Sutton, and H.L. Bhardwaj. 1991. Flooding reduces gas exchange and growth of snap bean. HortScience 26:372-373.

Stanley, C.D., T.C. Kaspar, and H.M. Taylor. 1980. Soybean top and root response to temporary water tables imposed at three different stages of growth. Agron. J. 72:341-346.

Steel, R.G.D. and J.H. Torrie. 1980. Principles and procedures of statistics. McGraw-Hill, New York.

Stoffella, P.J., R.F. Sandsted, R.W. Zobel, and W.L. Hymes. 1979. Root characteristics of black beans. II. Morphological differences among genotypes. Crop Sci. 19:826-830.

Tabbada, R.A. and M.A.A. Flores. 1982. Influence of soil water stress on vegetative and reproductive growth of Phaseolus vulgaris $c v$. White Babuio. Phillipines J. Biol. 11:266-272.

Trung, B.C., S. Yoshida, and Y. Kobayashi. 1985. Influence of excess soil moisture on the nitrogen nutrition and grain productivity of mungbean. Jpn. J. Crop Sci. 54:79-83.

Wadman-van Schravendijk, H., and O.M. van Andel. 1985. Interdependence of growth, water relations, and abscisic acid level in Phaseolus vulgaris during waterlogging. Physiol. Plant. 63:215-220.

Wample, R.L. and D.M. Reid. 1978. Control of adventitious production and hypocotyl hypertrophy of sunflower (Helianthus annuus) in response to flooding. Physiol. Plant. 44:351-358. 